\title{
Mitochondrial genome data confirm that yaks can serve as the intermediate host of Echinococcus canadensis (G10) on the Tibetan Plateau
}

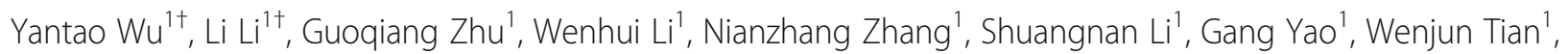
Baoquan $\mathrm{Fu}^{1}$, Hong Yin ${ }^{1}$, Xingquan $\mathrm{Zhu}^{1}$, Hongbin Yan ${ }^{1 *}$ and Wanzhong Jia ${ }^{1,2^{*}}$

\begin{abstract}
Background: Cervids used to be considered the only animal intermediate hosts of the G10 genotype of Echinococcus canadensis. Yaks are often herded in the Qinghai-Tibet Plateau, China, where echinococcosis remains prevalent. However, no E. canadensis G10 cases have been recorded in yaks until now. The aim of our study was to identify causative agents of echinococcosis in yaks in this region.

Methods: Total genomic DNA was extracted from the germinal layer of one hydatid using a Blood and Tissue Kit. Full-length mitochondrial (mt) cytochrome coxidase subunit 1 (cox1) and NADH dehydrogenase subunit 1 (nad1) genes were amplified by PCR. All purified PCR products were directly sequenced in both directions. Then seven pairs of overlap primers were designed to amplify the entire $\mathrm{mt}$ genome sequence of a suspected $E$. canadensis G10 isolate. Phylogenetic analyses were performed based on concatenated nucleotides from the 12 protein-coding genes of mt genomes of Echinococcus species in a Bayesian framework using MrBayes v3.1 and implementing the GTR + I + G model.

Results: Hydatids were found in yaks $(n=129)$ when organs were inspected at the slaughterhouse in Maqu county, Gannan Tibetan Autonomous Prefecture, Gansu Province, China in October 2016. Of these, 33 (25.6\%) harbored up to a dozen hydatid cysts. One cyst from each yak was characterized by sequencing its mitochondrial (mt) cox1 and nad 1 genes. On the basis of these sequence data, 32 cysts were identified as Echinococcus granulosus (sensu stricto) (G1-G3) and the remaining one was identified as the G10 genotype of E. canadensis. Its mt genome was then fully sequenced and compared with that of the G10 genotype in GenBank (AB745463). Phylogenetic analysis using complete $\mathrm{mt}$ genomes confirmed the Chinese cyst as belonging to the G10 genotype.

Conclusions: To our knowledge, this is the first report globally of E. canadensis (G10) from yaks in China, which suggests that the G10 genotype has a wider geographical distribution and broader host range than previously believed. This genotype has therefore potential risks to human health and animal husbandry.
\end{abstract}

Keywords: Echinococcus canadensis, G10 genotype, Yak, Mitochondrial genome

\footnotetext{
* Correspondence: yanhongbin@caas.cn; jiawanzhong@caas.cn

${ }^{\dagger}$ Equal contributors

${ }^{1}$ State Key Laboratory of Veterinary Etiological Biology/Key Laboratory of

Veterinary Parasitology of Gansu Province/Lanzhou Veterinary Research

Institute, Chinese Academy of Agricultural Sciences, Lanzhou 730046, Gansu

Province, People's Republic of China

Full list of author information is available at the end of the article
} 


\section{Background}

Cystic echinococcosis (CE) is one of the most important parasitic diseases in humans and one of the 17 neglected diseases (NTDs) prioritized by the World Health Organisation (WHO) in 2012. It is a widespread zoonosis caused by the cyst stage of Echinococcus granulosus (sensu lato) [1, 2]. Echinococcosis or hydatidosis affects various internal organs of terrestrial mammals including humans, livestock and wildlife [3].

Recent phylogenetic studies based on both mitochondrial and nuclear DNA genes show that E. granulosus (s.l.) is comprised of at least five independent species: E. granulosus (s.s.) (genotypes G1-G3), E. equinus (G4), E. ortleppi (G5), E. canadensis (G6-G10) and E. felidis [3-6]. Molecular and morphological studies suggest that it would be better if these E. granulosus (G6-G10) be re-classified as a separate species (i.e. E. canadensis) [5, 7-10]. These E. canadensis genotypes closely match the intermediate host-associated strains described in the earlier reports where E. canadensis G10 was named as cervid strain [11], which was first found in cervids in northeastern Finland representing a distinct genotype [12]. Cervids used to be thought the only animal intermediate host of G10 genotype of E. canadensis. However, a human case of the G10 type was recently reported in China [2].

Its milk, meat, dung and wool make the yak important for native herdsmen on the Qinghai-Tibet Plateau, where echinococcosis remains prevalent [13-16]. It has been reported that only E. granulosus (s.s.) and E. canadensis (G6) were observed in yaks [17-21]. Nevertheless, no $E$. canadensis G10 cases have been recorded in yaks until now. The aim of our study was to identify the causative agents of echinococcosis in yaks in this region. We characterized yak-derived $\mathrm{CE}$ isolates by sequencing selected mitochondrial $(\mathrm{mt})$ genes or the entire $\mathrm{mt}$ genome and speculated on possible transmission routes of $\mathrm{CE}$.

\section{Methods}

From August to October each year, many yaks and Tibetan sheep from grazing areas on the Qinghai-Tibet Plateau are slaughtered for human consumption at local slaughterhouses. We collected CE cyst specimens from yaks at a slaughterhouse near Maqu City in Maqu County, Gannan Tibetan Autonomous Prefecture, Gansu Province, China, in October 2016. The slaughterhouse $\left(33^{\circ} 59^{\prime} 30^{\prime \prime} \mathrm{N}, 102^{\circ} 4^{\prime} 7^{\prime \prime} \mathrm{E}\right.$; $3490 \mathrm{~m}$ above sea level) is situated near the eastern end of the plateau.

The surface of each cyst was cleaned with $75 \%$ alcohol cotton balls. Then, in the ultra-clean bench, the endocyst was repeatedly washed out with a phosphate buffer solution and the washings transferred to $1.5 \mathrm{ml}$ sterile centrifuge tubes using a sterile syringe. The tubes were centrifuged at $3000 \times g$ for $10 \mathrm{~min}$ at room temperature. After the supernatant was poured out, a wet preparation of the sediment was examined for the presence of protoscolices under a microscope. Total genomic DNA was extracted from the germinal layer of the cyst using a Qiagen Blood and Tissue Kit (Qiagen, Hilden, Germany) according to the manufacturer's instructions and eluted into $100 \mu \mathrm{l} \mathrm{H}_{2} \mathrm{O}$, followed by RNase treatment step, and was stored at $-20{ }^{\circ} \mathrm{C}$ until use.

Full-length cox $1(\sim 1853 \mathrm{bp})$ and nad1 ( 1286 bp) genes were amplified using the primer pairs $5^{\prime}$-GAA AAT TGT GGA GTT ACT GCT-3' / 5'-AAG CAT GAT GCA AAA GGC AAA TAA ACC-3' for the cox 1 and 5'-ATT ATA GAA AAT TTT CGT TTT ACA CGC-3' / 5'-ATT CAC AAT TTA CTA TAT CAA AGT AAC C-3' for the nad1. Cycling parameters for both were as follows: an initial denaturation step at $94{ }^{\circ} \mathrm{C}$ for 4 min, 35 cycles at $98{ }^{\circ} \mathrm{C}$ for $15 \mathrm{~s}, 52-55^{\circ} \mathrm{C}$ for $30 \mathrm{~s}$, and $72{ }^{\circ} \mathrm{C}$ for $2 \mathrm{~min}$, followed by a final extension step at $72{ }^{\circ} \mathrm{C}$ for $10 \mathrm{~min}$. Each PCR reaction yielded a single band detected in a $1.0 \%(w / v)$ agarose gel stained with GelRed. Each PCR product was purified for sequencing by gel-cut and DNA was recovered through a column according to the manufacturer's instructions (AxyPrep DNA Gel Extraction Kit by AxyGen, Suzhou, China). All purified PCR products were directly sequenced in both directions using Sanger dideoxy chain termination in an ABI 3730 DNA sequencer at Sangon Company (Shanghai, China). The PCR primers were used as sequencing primers. All the raw sequences were assembled using the software package Chromas, edited and blasted online (https://blast.ncbi.nlm.nih.gov/Blast.cgi?PAGE_TY $\mathrm{PE}=\mathrm{BlastSearch}$ ) to determine the Echinococcus species or genotype of each cyst sample.

A single complete $\mathrm{mt}$ genome was sequenced to further confirm whether a cyst $(\sim 2 \mathrm{~cm}$ in diameter $)$ (Specimen 1) belonged to the G10 genotype of $E$. canadensis. Seven pairs of oligonucleotide primers were designed based on the conserved regions from published complete mtDNA sequences of E. shiquicus, $E$. multilocularis, E. equinus, E. ortleppi, E. granulosus (s.s.) (G1-G3), E. granulosus (s.l.) (G6-G10) (Tables 1 and 2). The overlapping PCR products amplified by these primers, ranging from $1885 \mathrm{bp}$ to $2622 \mathrm{bp}$ in length, covered the entire $\mathrm{mt}$ genome of Specimen 1. PCR reactions were carried out using a standard 3-step regime: $94{ }^{\circ} \mathrm{C}$ for $4 \mathrm{~min}$ (initial denaturation), 35 cycles of $98{ }^{\circ} \mathrm{C}$ for $30 \mathrm{~s}$ (denaturation), $52-56{ }^{\circ} \mathrm{C}$ for $30 \mathrm{~s}$ (annealing), $72{ }^{\circ} \mathrm{C}$ for $3 \mathrm{~min}$ (extension), followed by a final hold at $72{ }^{\circ} \mathrm{C}$ for $10 \mathrm{~min}$. Sequencing and assembly were as above. The mt genome sequence was annotated through alignment with the complete mtDNA sequence of E. canadensis (G10) (AB745463).

Phylogenetic analyses were performed using concatenated nucleotides from the 12 protein-coding genes of the mt genomes of E. canadensis (G10) and 
Table 1 The mitochondrial genomes of Echinococcus spp. used for inference of the phylogenetic tree

\begin{tabular}{lllll}
\hline Genotype/species & Size (bp) & Host & GenBank ID & Origin \\
\hline G1/E. granulosus (s.s.) & 13,588 & Sheep & AF297617 & UK \\
G4/E. equinus & 13,598 & Horse & AF346403 & UK \\
G5/E. ortleppi & 13,717 & Cattle & AB235846 & Argentina \\
G6/E. canadensis & 13,721 & Camel & AB208063 & Kazakhstan \\
G7/E. canadensis & 13,719 & Pig & AB235847 & Poland \\
G8/E. canadensis & 13,717 & Moose & AB235848 & USA \\
G10/E. canadensis & 13,720 & Moose & AB745463 & Finland \\
E. felidis & 13,632 & NC021144 & Uganda \\
E. multilocularis & 13,738 & ABO18440 & Japan \\
E. oligarthrus & 13,791 & Vole & AB208545 & Panama \\
E. shiquicus & 13,807 & Laboratory mice & AB208064 & China \\
E. vogeli & 13,791 & O. curzoniae & AB208546 & Colombia \\
T. solium & 13,709 & Unknown & AB086256 & China \\
G10/E. canadensis Yak GS & 13,603 & Pig & MG597240 & China (this study) \\
\hline
\end{tabular}

Table 2 Primers for amplification of seven overlapping DNA fragments and their positions in the mtDNA of Echinococcus (G10) isolate from Gansu, China, and four additional primer pairs used to amplify a region containing SNR. The positions of the primers are based on the $m t$ genome sequence of $E$. canadensis (G10; AB745463)

\begin{tabular}{|c|c|c|c|}
\hline Primer name & Primer sequence $\left(5^{\prime} \rightarrow 3^{\prime}\right)$ & Positions on the H-strand & Size of PCR product (bp) \\
\hline F1 & TTGTAAAGATGCCAGAAAA & $244-266$ & 2110 \\
\hline R1 & AYCTAGATCATITIIITGGA & $2337-2356$ & \\
\hline $\mathrm{F} 2$ & GCCCCATATATGTATAGTAT & $2225-2244$ & 1962 \\
\hline R2 & TATACACCGAAGAATAGCAT & 3897-3916 & \\
\hline F3 & GATTTRGTGTATTITCATTCRTA & $3710-3732$ & 2508 \\
\hline R3 & CCAAAACACCCTAACCTAATAT & $6196-6217$ & \\
\hline F4 & ATCGTTGCCWTATTGTTATAG & $5965-5986$ & 2622 \\
\hline R4 & TAACGGAAAATAAATTCACA & $8567-8586$ & \\
\hline F5 & TGCTGTTAACTTCAAGAAATGG & $8418-8439$ & 1885 \\
\hline R5 & ACATAACATAATGAAAATGAGC & $10,281-10,302$ & \\
\hline F6 & ATATGTITACTGTTGGGTTRGAT & $10,027-10,049$ & 2352 \\
\hline R6 & GCAGCACATAGACTTGGCTT & $12,360-12,379$ & \\
\hline F7 & CATCTGCGGTTARTCTGTITTC & $12,036-12,057$ & 2143 \\
\hline R7 & TAATGCTTAAAACTAACTCATA & $437-458$ & \\
\hline F8 & TTATTITGTGTCGGTGTTTG & $13,448-13,469$ & 1387 \\
\hline R8 & CCCGCATAGCCTCCAACAA & $1096-1114$ & \\
\hline F9 & TTCTGGTGTTAAGTGTTGTG & $13,659-13,678$ & 498 \\
\hline R9 & TAACTTCTGACATAGCTACC & $417-436$ & \\
\hline F10 & GGCTTGTGTGTATTATTTGG & $13,514-13,533$ & 793 \\
\hline R10 & ACAAACCTATACTAACACAC & $567-586$ & \\
\hline F11 & GGTGTTAAGTGTTGTGGCCAGAAA & $13,663-13,686$ & 530 \\
\hline R11 & GAAACATCCATAATTAATGCTTAAAACTAACTC & $440-472$ & \\
\hline
\end{tabular}


other Echinococcus species (Table 1) in a Bayesian framework using MrBayes v.3.1 [22] and implementing the GTR + I + G model of protein coding genes evolution as described previously [23]. The $\mathrm{mt}$ genome sequence of Taenia solium was used as the outgroup. MrBayes settings were lset nst $=6$, rates $=$ invgamma; two chains (temp $=0.2$ ) were run for 1,000,000 generations and sampled every 1000 generations. Convergence was assessed using Tracer v.1.4 [24], with a discarded 'burnin' period of 1000 trees. Nodal support was expressed using posterior probabilities.

\section{Results}

Of 129 yaks examined, 33 (25.6\%) harbored hydatid cysts. Thirty two cyst samples were identified as Echinococcus granulosus (s.s.) (G1-G3), while Specimen 1 was identified as belonging to the G10 genotype of E. canadensis (here designated Yak-GS). Our Specimen 1 (G10, Yak-GS), found near the right lobe margin of the yak's lung, contained protoscolices in hydatid fluid. The $\operatorname{cox} 1$ and nad 1 full-length gene sequences of this cyst showed a respective $99.75 \%$ and $99.36 \%$ similarity with those (GenBank: KJ663947 and KJ663949) from a 66-year-old female CE patient in northeastern China. Of the two base substitutions in the cox 1 gene, one, at position 425 (G to A), produced an amino acid change from tyrosine to cysteine. Of the five substitutions in the nad 1 gene, one, at position 522 (A to G), caused an amino acid change from cysteine to tryptophan (Table 3 ).

The mt genome of G10 (Yak-GS) (MG597240) was $13,603 \mathrm{bp}$ in length and A + T-rich (67.67\%). The $\mathrm{mt}$ genome sequence of G10 (Yak-GS) had 99.6\% identity with that of the previously reported cervid strain (13,720 bp in length): the main difference was less 117 bp from the sequence (GenBank: AB745463) occurred in the short non-coding region (SNR) located between tRNA-Tyr and tRNA-Leu. In order to further confirm the difference, four more primer pairs (F8-R8 to F11-R11 in Table 2) were used to amplify a region containing SNR.

The Bayesian tree inferred from concatenated nucleotides of the 12 protein-coding genes of the mt genomes is shown in Fig. 1. This tree demonstrated strong support for each species or genotype of Echinococcus. The

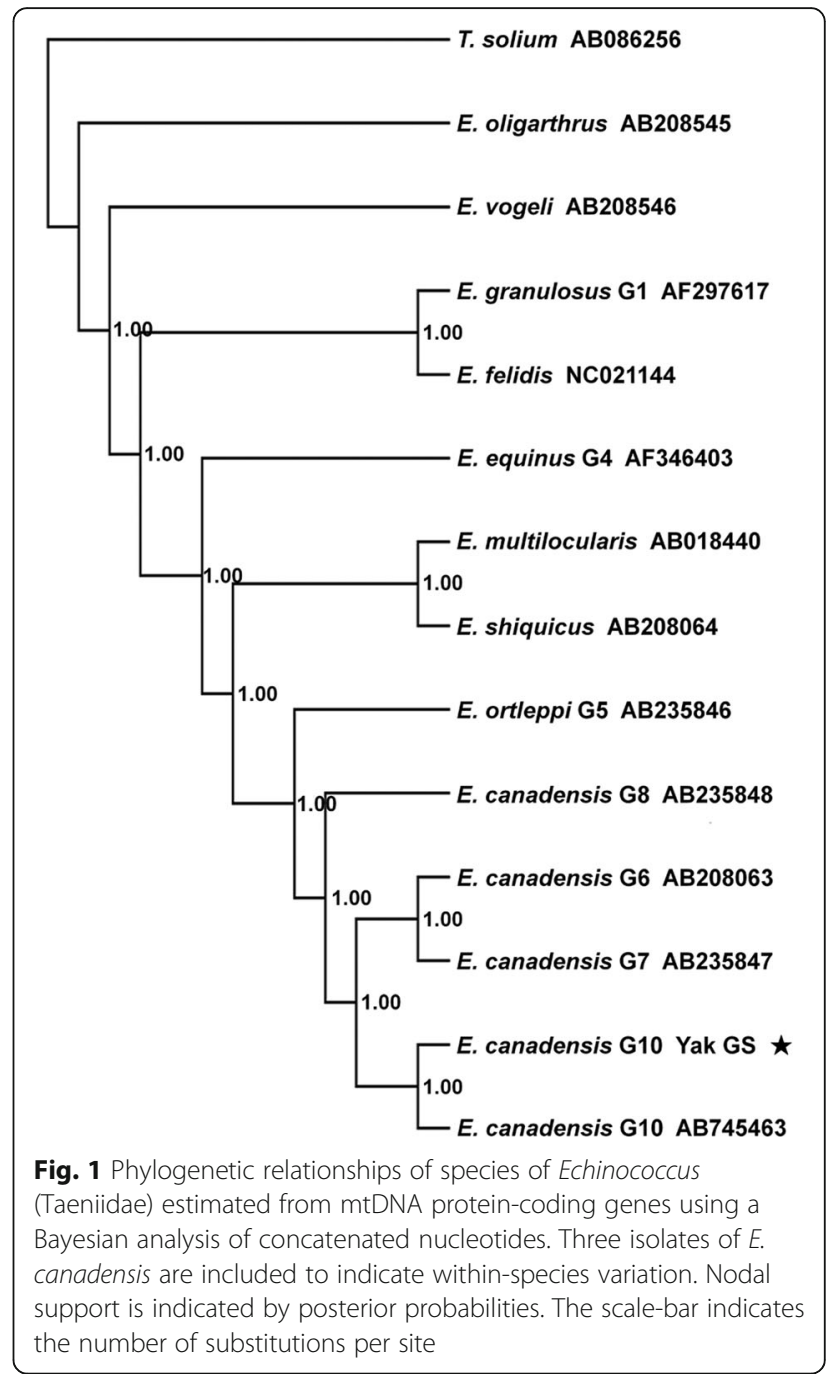

Yak-GS sequence was a sister to E. canadensis G10 (GenBank: AB745463) with posterior support value of $100 \%$. This confirms Yak-GS as belonging to E. canadensis G10.

\section{Discussion}

Echinococcus canadensis (G10) was first discovered and named in northeastern Finland based on five isolates of cervid origin $[12,25]$. Adults and larvae of $E$. canadensis G10 were identified in wolves and dogs as definitive hosts, and three deer species (reindeer, moose and elk)

Table 3 Differences in nucleotides and amino acids at the cox 1 and nad 1 loci of $E$. canadensis G10 between the sequences from Yak_GS (MG597240) and a cystic echinococcosis patient of NE China (KJ663947)

\begin{tabular}{llcl}
\hline Gene & GenBank ID & No. of mutations (\% similarity) & Codon (amino acid)/Nucleotide position ${ }^{{ }^{2}}$ \\
\hline cox1 & KJ663947 & $2(99.75)$ & TAT (Y)/425; GGA(G)/888 \\
& MG597240 & & TGT (C)/425; GGG(G)/888 \\
nad1 & KJ663949 & $5(99.36)$ & GGC (G)/117; AGC (S)/207; GGT (G)/231; GTG (V)/315; TGG (W)/522 \\
& MG597240 & & GGT (G)/117; AGT (S)/207; GGC (G)/231; GTA (V)/315; TGT (C)/522
\end{tabular}

Abbreviations: $Y$ tyrosine, $G$ glycine, $C$ cysteine, $S$ serine, $V$ valine, $W$ tryptophan

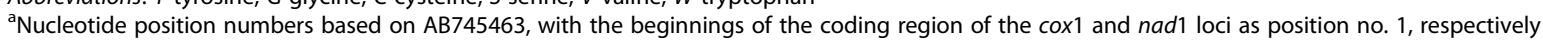


as intermediate hosts, using molecular genetic techniques $[2,3,8,9,12,26-34]$. The wolf as the typical definitive host of E. canadensis (G10) is an opportunity predator, and the availability of prey and the degree of difficulty in its acquisition determine the diet composition [35]. Thus, wolves have different diets in the different regions [36]. The typical life-cycle of this genotype was "wolf-cervid", which has been clarified using molecular methods in Estonia, Mongolia, USA, Canada, Finland, Sweden and Russia [3, 8, 9, 12, 28-33, 37, 38]. Wolves on the Tibetan Plateau mainly prey on hares, yaks and small rodents in the plant green period, and mainly prey on yaks, sheep and hares in the plant withering period [36, 39]. There are many species of cervids living on the Tibetan Plateau, such as the white-lipped deer (Gervus albirostris), red deer (Cervus elaphus), Fea's muntjac (Muntiacus feae), etc. [40, 41]. Until now, however, there was no report on the infection of Echinococcus species in cervids, and whether the wolf-cervid cycle exists in this region and needs further study. In addition, a "dog-cervid" life-cycle has been reported in Canada and Finland where dogs had access to offal and carcasses [8, 29-32, 34, 37].

In recent years, E. canadensis (G10) has been reported in humans in three countries: Mongolia (2010, 2013), Russia (2014) and Finland (2015) [26-28, 34]. In 2014, a cyst from a 66-year-old female CE patient in Northeastern China's Heilongjiang Province was also identified as E. canadensis (G10) using cox1 and nad 1 genes. This was the first report of the G10 genotype of E. canadensis from humans in China. However, the life-cycle of the G10 genotype in this area remains unknown [2]. The cox1 gene sequence from this patient (GenBank: KJ663947) was identical with those from wolves in Mongolia, suggesting involvement of this species in China. We have not identified any dogs infected with G10 in China in studies carried out at our laboratory in recent years [2]. However, a "dog-livestock" life-cycle of the G10 genotype cannot be ruled out in Gannan Tibetan Autonomous Prefecture or neighboring regions.

The yak (Bos grunniens), a bovid species, inhabits steppes of the Himalayan highlands and was domesticated on the Tibetan plateau about 3000 years ago [42]. More than 14 million domestic yaks live on the QinghaiTibetan Plateau in China, accounting for about 95\% of the world yak population $[15,43,44]$. The native people totally depend on their yaks herd to support their livelihood [14]. Due to the physical environment and socioeconomic situation, herdsmen in this locality classified as 'semi-nomadic' practice a nomadic lifestyle for most months of the year and yaks graze only on natural pasture throughout the year and are not offered supplements $[43,45,46]$. Local herdsmen reside in permanent dwellings usually within or close to large settlements during the winter, while they move yaks to summer pastureland where there are no permanent settlements in spring [45]. Dogs are also important to protect herders and their livestock. Influenced by local customs, freeroaming dogs are very commonly seen in Tibetan areas, even in urban places like Lhasa, Yushu and other cities. The native Tibetan pastoralists tend to kill and process domesticated livestock themselves [14, 47]. The fresh internal organs (offal) of yaks and sheep are discarded carelessly, often being eaten by dogs $[14,48]$, which undoubtedly increases the risk of transmission of hydatid disease. Therefore, in these areas humans probably acquire hydatid infection mostly through the yak-dog cycle. In order to prevent the transmission of echinococcosis in this region, we strongly suggest better control and management of both family dogs and stray dog populations, improvement of slaughter hygiene management with more careful inspection and handling of offal.

Currently, wolves and dogs are known to be the definitive hosts, and cervids (moose, elk and reindeer) are generally considered the only animal intermediate hosts of E. canadensis (G10) [2, 3, 8, 9, 12, 25-33]. On the Qinghai-Tibet Plateau, where echinococcosis remains prevalent, E. granulosus (s.s.) has been found in humans, sheep, yaks, cattle, dogs and Tibetan pigs [13, 15, 17-20, 48-51], and E. canadensis (G6) has been found in cattle, camels, yaks, goats and dogs [52-54]. Despite this, to our knowledge there has never been a report of E. canadensis (G10). Therefore, in the present study, we confirmed for the first time that yak can also serve as the intermediate host of E. canadensis (G10) and also observed some protoscolices in the cyst. However, the true transmission pattern of this genotype needs to be determined by further epidemiological and molecular investigations of animals as definitive and intermediate hosts in the Qinghai-Tibet Plateau. The identification of the G10 genotype of $E$. canadensis in the yak in China shows that this genotype possibly has a wider geographical distribution and broad host range than expected.

There are many domestic yaks and some wild yaks on the Tibetan plateau, which provide a great possibility for the spread of E. canadensis (G10). Approximately 22,000 wild yaks live in China, accounting for $90 \%$ of the world's total population [44]. These wild yaks are mainly distributed on the Tibet Plateau [44, 55-59], but it is unclear whether the present finding in a yak was a spillover from a wildlife-cycle [60]. Our study is not only a warning for native people to be aware of the disease, but also has significance for the study of $E$. canadensis (G10) globally. Further studies are necessary to determine host range and specificity, geographical distribution, transmission dynamics, infectivity to animal and humans, etc. of this genotype in China. 


\section{Conclusions}

We have confirmed for the first time globally that $E$. canadensis (G10) can use yaks as the intermediate host and form fertile cysts containing protoscoleces in yaks. This suggests that the G10 genotype have a wider geographical distribution and broader host range than previously believed and reported, and that this genotype pose potential risks to human health and animal husbandry. Therefore, our study has important significance for further studying E. canadensis (G10) across the world.

\section{Abbreviations}

CAAS: Chinese Academy of Agricultural Sciences; CE: Cystic echinococcosis; DNA: Deoxyribonucleic acid; NTD: Neglected tropical disease;

PCR: Polymerase chain reaction; SNR: Short non-coding region; WHO: World Health Organisation

\section{Acknowledgements}

We thank Fuheng Zhang and Mingkuan Guo from the Maqu Animal Disease Prevention and Control Center, Gansu Province and Dianwen Zhu from Maqu Animal Health Supervision Institute, Gansu Province for their support in the collection of cyst samples. Also, we thank Professor David Blair from the School of Marine and Tropical Biology, James Cook University, Australia, for his comments, modifications and advice.

\section{Funding}

This study was supported by National Key Basic Research Program (973 Program) of China (2015CB150300), the National Natural Science Foundation of China (NSFC, 31401148, 31402191), the Gansu Provincial Key Science and Technology Projects (1203NKDA039) and NBCITS, MOA (CARS-38).

\section{Availability of data and materials}

The data supporting the conclusions of this article are included within the article. A complete mitochondrial genome sequence is submitted to the GenBank database under the accession number MG597240.

\section{Authors' contributions}

YTW, WZJ, LL and HBY designed the study. YTW, WZJ, HBY, LL, GQZ, SNL, GY NZZ, WHL and WJT undertook sample collection. YTW, WZJ, LL, XQZ and HBY conducted the laboratory and data analysis. YTW drafted the manuscript, with subsequent input from WZJ, HBY and HY. All authors read and approved the final manuscript.

Ethics approval and consent to participate Not applicable.

\section{Consent for publication}

Not applicable.

\section{Competing interests}

The authors declare that they have no competing interests.

\section{Publisher's Note}

Springer Nature remains neutral with regard to jurisdictional claims in published maps and institutional affiliations.

\footnotetext{
Author details

${ }^{1}$ State Key Laboratory of Veterinary Etiological Biology/Key Laboratory of Veterinary Parasitology of Gansu Province/Lanzhou Veterinary Research Institute, Chinese Academy of Agricultural Sciences, Lanzhou 730046, Gansu Province, People's Republic of China. ${ }^{2}$ Jiangsu Co-innovation Center for Prevention and Control of Important Animal Infectious Disease, Yangzhou 225009, Jiangsu Province, People's Republic of China
}

Received: 20 October 2017 Accepted: 29 January 2018

Published online: 09 March 2018

\section{References}

1. Rodriguez-Prado U, Jimenez-Gonzalez DE, Avila G, Gonzalez AE, MartinezFlores WA, Mondragon de la Pena C, et al. Short report: genetic variation of Echinococcus canadensis (G7) in Mexico. Am J Trop Med Hyg. 2014;91(6): 1149-53.

2. Yang D, Zhang TM, Zeng ZL, Zhao W, Zhang WZ, Liu AQ. The first report of human-derived G10 genotype of Echinococcus canadensis in China and possible sources and routes of transmission. Parasitol Int 2015:64(5):330-3.

3. Nakao M, Yanagida T, Konyaev S, Lavikainen A, Odnokurtsev VA, Zaikov VA, et al. Mitochondrial phylogeny of the genus Echinococcus (Cestoda: Taeniidae) with emphasis on relationships among Echinococcus canadensis genotypes. Parasitology. 2013;140(13):1625-36.

4. Knapp J, Nakao M, Yanagida T, Okamoto M, Saarma U, Lavikainen A, et al. Phylogenetic relationships within Echinococcus and Taenia tapeworms (Cestoda: Taeniidae): an inference from nuclear protein-coding genes. Mol Phylogenet Evol. 2011;61(3):628-38

5. Nakao M, McManus DP, Schantz PM, Craig PS, Ito A. A molecular phylogeny of the genus Echinococcus inferred from complete mitochondrial genomes. Parasitology. 2007:134(5):713-22.

6. Thompson RC, McManus DP. Towards a taxonomic revision of the genus Echinococcus. Trends Parasitol. 2002:18(10):452-7.

7. Williams RJ, Sweatman GK. On the transmission, biology and morphology of Echinococcus granulosus equinus, a new subspecies of hydatid tapeworm in horses in great Britain. Parasitology. 1963:53:391-407.

8. Thompson RC, Boxell AC, Ralston BJ, Constantine CC, Hobbs RP, Shury T, et al. Molecular and morphological characterization of Echinococcus in cervids from North America. Parasitology. 2006;132(3):439-47.

9. Moks E, Jogisalu I, Valdmann H, Saarma U. First report of Echinococcus granulosus G8 in Eurasia and a reappraisal of the phylogenetic relationships of 'genotypes' G5-G10. Parasitology. 2008;135(5):647-54.

10. Yanagida T, Lavikainen A, Hoberg EP, Konyaev S, Ito A, Sato MO, et al. Specific status of Echinococcus canadensis (Cestoda: Taeniidae) inferred from nuclear and mitochondrial gene sequences. Int J Parasitol. 2017;47(14):971-9.

11. Laurimaa L, Davison J, Suld K, Plumer L, Oja R, Moks E, et al. First report of highly pathogenic Echinococcus granulosus genotype $\mathrm{G} 1$ in dogs in a European urban environment. Parasit Vectors. 2015:8:182

12. Lavikainen A, Lehtinen MJ, Meri T, Hirvel-Koski V, Meri S. Molecular genetic characterization of the Fennoscandian cervid strain, a new genotypic group (G10) of Echinococcus granulosus. Parasitology. 2003;127(3):207-15.

13. Li K, Gao JF, Shahzad M, Han ZQ, Nabi F, Liu MY, et al. Seroprevalence of Toxoplasma gondii infection in yaks (Bos grunniens) on the Qinghai-Tibetan plateau of China. Vet Parasitol. 2014;205(1-2):354-6.

14. Xiao N, Qiu JM, Nakao M, Nakaya K, Yamasaki H, Sako Y, et al. Identification of Echinococcus species from a yak in the Qinghai-Tibet plateau region of China. Am J Trop Med Hyg. 2003;69(4):445-6.

15. Li K, Zhang LH, Zhang H, Lei ZX, Luo HQ, Mehmood K, et al. Epidemiological investigation and risk factors of Echinococcus granulosus in yaks (Bos grunniens), Tibetan pigs and Tibetans on Qinghai Tibetan plateau. Acta Trop. 2017:173:147-52.

16. Li K, Lan YF, Luo HQ, Zhang H, Liu DY, Zhang LH, et al. Prevalence, associated risk factors, and phylogenetic analysis of Toxocara vitulorum infection in yaks on the Qinghai Tibetan plateau, China. Korean J Parasitol. 2016:54(5):645-52

17. Yang YR, Rosenzvit M, Zhang LH, Zhang JZ, McManus D. Molecular study of Echinococcus in west-central China. Parasitology. 2005;131(4):547-55.

18. Yan N, Nie HM, Jiang ZR, Yang AG, Deng SJ, Guo L, et al. Genetic variability of Echinococcus granulosus from the Tibetan Plateau inferred by mitochondrial DNA sequences. Vet Parasitol. 2013:196(1-2):179-83.

19. Zhong XQ, Wang N, Hu DD, Wang JH, Liu TY, Gu XB, et al. Sequence analysis of cytb gene in Echinococcus granulosus from western China. Korean J Parasitol. 2014;52(2):205-9.

20. Ma SM, Maillard S, Zhao HL, Huang X, Wang H, Geng PL, et al. Assessment of Echinococcus granulosus polymorphism in Qinghai Province, People's Republic of China. Parasitol Res. 2008:102(6):1201-6.

21. Ma RL, Lou ZZ, Li L, Hu GW, Zhao QB, Shen YL, et al. Study on the polymorphism of mitochondrial cox 1 gene and nad 1 gene in Echinococcus granulosus in Qinghai, China. Vet Sci China. 2014;44(12):1251-6. 
22. Ronquist F, Huelsenbeck JP. MrBayes 3: Bayesian phylogenetic inference under mixed models. Bioinformatics. 2003;19(12):1572-4.

23. Jia WZ, Yan HB, Guo AJ, Zhu XQ, Wang YC, Shi WG, et al. Complete mitochondrial genomes of Taenia multiceps, T. hydatigena and T. pisiformis: additional molecular markers for a tapeworm genus of human and animal health significance. BMC Genomics. 2010;11:447.

24. Drummond AJ, Ho SY, Phillips MJ, Rambaut A. Relaxed phylogenetics and dating with confidence. PLoS Biol. 2006;4(5):e88.

25. Lavikainen A, Lehtinen MJ, Laaksonen S, Agren E, Oksanen A, Meri S. Molecular characterization of Echinococcus isolates of cervid origin from Finland and Sweden. Parasitology. 2006;133(5):565-70.

26. Jabbar A, Narankhajid M, Nolan MJ, Jex AR, Campbell BE, Gasser RB. A first insight into the genotypes of Echinococcus granulosus from humans in Mongolia. Mol Cell Probes. 2011;25(1):49-54.

27. Ito A, Dorjsuren T, Davaasuren A, Yanagida T, Sako Y, Nakaya K, et al. Cystic echinococcoses in Mongolia: molecular identification, serology and risk factors. PLoS Negl Trop Dis. 2014;8(6):e2937.

28. Konyaev SV, Yanagida T, Nakao M, Ingovatova GM, Shoykhet YN, Bondarev AY, et al. Genetic diversity of Echinococcus spp. in Russia. Parasitology. 2013; 140(13):1637-47.

29. Himsworth CG, Jenkins E, Hill JE, Nsungu M, Ndao M, Andrew Thompson $\mathrm{RC}$, et al. Emergence of sylvatic Echinococcus granulosus as a parasitic zoonosis of public health concern in an indigenous community in Canada. Am J Trop Med Hyg. 2010;82(4):643-5.

30. Schurer J, Shury T, Leighton F, Jenkins E. Surveillance for Echinococcus canadensis genotypes in Canadian ungulates. Int J Parasitol Parasites Wildl. 2013;2:97-101

31. Schurer JM, Gesy KM, Elkin BT, Jenkins EJ. Echinococcus multilocularis and Echinococcus canadensis in wolves from western Canada. Parasitology. 2014; 141(2):159-63.

32. Bryan HM, Darimont CT, Hill JE, Paquet PC, Thompson RC, Wagner B, et al. Seasonal and biogeographical patterns of gastrointestinal parasites in large carnivores: wolves in a coastal archipelago. Parasitology. 2012;139(6):781-90.

33. Moks E, Jogisalu I, Saarma U, Talvik H, Jarvis T, Valdmann H. Helminthologic survey of the wolf (Canis lupus) in Estonia, with an emphasis on Echinococcus granulosus. J Wildl Dis. 2006:42(2):359-65.

34. Hamalainen S, Kantele A, Arvonen M, Hakala T, Karhukorpi J, Heikkinen J, et al. An autochthonous case of cystic echinococcosis in Finland, 2015. Euro Surveill. 2015;20(42):2-5.

35. Carbyn LN. Gray wolf and red wolf. In: Nowak M, Baker JA, Obbard ME, Malloch B, editors. Wild furbearer management and conservation in North America. Ontario: Ministry of Natural Resources; 1987. p. 358-77.

36. Liu BW, Jiang ZG. Diet composition of wolves Canis lupus in the northeastern Qinghai-Tibet plateau, China. Acta Theriol. 2003;48(2):255-63.

37. Deplazes P, Rinaldi L, Alvarez Rojas CA, Torgerson PR, Harandi MF, Romig T, et al. Global distribution of alveolar and cystic echinococcosis. Adv Parasitol. 2017:95:315-493.

38. Ito A, Chuluunbaatar G, Yanagida T, Davaasuren A, Sumiya B, Asakawa M, et al. Echinococcus species from red foxes, corsac foxes, and wolves in Mongolia. Parasitology. 2013;140(13):1648-54.

39. Liu BW, Jiang ZG. Diet composition of wolf in the Qinghai Lake region in northeast Tibetan Plateau. J Clin Endocrinol Metab. 2003;86(5):2320-2.

40. Song SL. Cervidae in China. Spec Econ Anim Plant. 2008;11(1):10.

41. Zhang B. Wild Cervidae in China. Biology Teaching. 2008;33(6):2-4.

42. Nowak RM. Artiodactyla; Bovidae; Genus Bos. In: Nowak RM, editor. Walker's mammals of the world. Baltimore and London: The Johns Hopkins University Press; 1991. p. 1424-31.

43. Cui GX, Yuan F, Degen AA, Liu SM, Zhou JW, Shang ZH, et al. Composition of the milk of yaks raised at different altitudes on the Qinghai-Tibetan plateau. Int Dairy J. 2016;59:29-35.

44. Shi QJ, Guo YY, Engelhardt SC, Weladji RB, Zhou Y, Long M, et al. Endangered wild yak (Bos grunniens) in the Tibetan plateau and adjacent regions: population size, distribution, conservation perspectives and its relation to the domestic subspecies. J Nat Conserv. 2016:32:35-43.

45. Budke CM, Campos-Ponce M, Qian W, Torgerson PR. A canine purgation study and risk factor analysis for echinococcosis in a high endemic region of the Tibetan Plateau. Vet Parasitol. 2005;127(1):43-9.

46. Schantz PM, Wang H, Qiu JM, Liu FJ, Saito E, Emshoff A, et al. Echinococcosis on the Tibetan plateau: prevalence and risk factors for cystic and alveolar echinococcosis in Tibetan populations in Qinghai Province, China. Parasitology. 2003;127(7):S107-8.
47. Qiu JM, Chen HC, Chen XW, Liu GH. Natural Alveolaris echinococcus infection in yarks and sheep in Shiqu County, Sichuan Province. Endemic Dis Bull. 1989;4:26-9.

48. Ma JY, Wang H, Lin GH, Zhao F, Li C, Zhang TZ, et al. Surveillance of Echinococcus isolates from Qinghai, China. Vet Parasitol. 2015;207(1-2):44-8.

49. Wang $N$, Wang JH, Hu DD, Zhong $X Q$, Jiang $Z G$, Yang $A G$, et al. Genetic variability of Echinococcus granulosus based on the mitochondrial $16 \mathrm{~S}$ ribosomal RNA gene. Mitochondrial DNA. 2015;26(3):396-401.

50. Boufana B, Lett W, Lahmar S, Griffiths A, Jenkins DJ, Buishi I, et al. Canine echinococcosis: genetic diversity of Echinococcus granulosus sensu stricto (s.s.) from definitive hosts. J Helminthol. 2015:89(6):689-98.

51. Nakao M, Li TY, Han XM, Ma XM, Xiao N, Qiu JM, et al. Genetic polymorphisms of Echinococcus tapeworms in China as determined by mitochondrial and nuclear DNA sequences. Int J Parasitol. 2010;40(3):379-85.

52. Zhang LH, Chai JJ, Jiao W, Osman Y, McManus DP. Mitochondrial genomic markers confirm the presence of the camel strain (G6 genotype) of Echinococcus granulosus in north-western China. Parasitology. 1998;116(1):29-33.

53. Liu Q, Cao LL, Zhang YG, Xu D, Shang LM, Wang XL, et al. Genotypes of Echinococcus granulosus in animals from Yushu, northeastern China. Vector Borne Zoonotic Dis. 2013;13(2):134-7.

54. Bart JM, Knapp J, Gottstein B, El-Garch F, Giraudoux P, Glowatzki ML, et al. EmsB, a tandem repeated multi-loci microsatellite, new tool to investigate the genetic diversity of Echinococcus multilocularis. Infect Genet Evol. 2006;6(5):390.

55. Dong SK, Wu XY, Liu SL, Su XK, Wu Y, Shi JB, et al. Estimation of ecological carrying capacity for wild yak, kiang, and Tibetan antelope based on habitat suitability in the Aerjin Mountain Nature Reserve, China. Acta Ecol Sin. 2015; 35(23):7598-607.

56. Wang ZF, Shen X, Liu B, Su JP, Yonezawa, Yu Y, et. Phylogeographical analyses of domestic and wild yaks based on mitochondrial DNA: new data and reappraisal. J Phylogeogr. 2010;37(12):2332-44.

57. Lu FY, Shi JB, Zhang ZH, Su XK, Wu Y, Dong SK, et al. The number and distribution area of Tibetan antelopes, wild yaks and Tibetan wild asses in Aerjin Mountain natural protection. J Beijing Norm Univ (Natural Science Edition). 2015;51(4):374-81

58. Zhang ZG, Xia L, Yang QS. Distribution and protection of yaks, China. Chin J Zool. 2009;44(1):148-50.

59. Yao J, Yang BH, Yan P, Liang CN, Guo J, Jiao S, et al. Analysis of habitat environment and population behavior of wild yaks in China. Acta Prataculturae Sinica. 2006;15(2):124-8.

60. Hu HH, Wu WP, Wang LY, Wang Q, Huang Y, Guan YY. Study of infection of Echinococcus granulosus in yak in spring and its potential role in transmission of cystic echinococcosis in Rangtang County of Sichuan, China. Biomed Environ Sci. 2013;26(3):226-9.

\section{Submit your next manuscript to BioMed Central and we will help you at every step:}

- We accept pre-submission inquiries

- Our selector tool helps you to find the most relevant journal

- We provide round the clock customer support

- Convenient online submission

- Thorough peer review

- Inclusion in PubMed and all major indexing services

- Maximum visibility for your research

Submit your manuscript at www.biomedcentral.com/submit
) Biomed Central 